\title{
The local economic development processes in low-income countries: The case of the metropolis of Chegutu in Zimbabwe
}

\begin{abstract}
Local authorities are widely regarded as catalysts accelerating localised processes of economic development in industrialised countries but in low-income countries they are perceived as dysfunctional, inefficient and ineffective in meeting and addressing societal demands. This abstract view is however, not grounded in empirical research. As such, utilising the case of the metropolis of Chegutu a survey was designed to empirically explicate the economic processes militating its economic development. The findings are useful to policy-makers, local government authorities and management scholars. The study's unique contribution lies in its examination of the processes of local economic development in a low-income country.
\end{abstract}

Keywords: low-income countries; LED; Chegutu; metropolis; economic planning; policy-makers; local authority

\section{INTRODUCTION}

As the world's economy continues to deteriorate, localised processes of economic development can be used as conduits for stimulating and accelerating economic development at local, national and international levels. Consistent with this Blakely (1994, p.xiv) expressed that localised processes of economic development 'stimulate local employment opportunities in sectors that improve the community using existing human, natural and institutional resources'. Similarly, the World Bank (2008b) emphasised that localised economic processes should build-up the economic capacity of a local area in order to shape the economic future and the quality of life for all. Quite clearly, this is a process in which public, business and non-governmental sector partners collaborate to create better conditions for economic growth and employment generation (World Bank, 2008a; 2008b). 
Indeed, local economic development (LED) - a term widely used in the literature to refer to localised processes of economic development denotes a system whereby local authorities engage with various stakeholders including the business community and the general population to stimulate or maintain business activity and/or employment (Kuklinski, 1970). Admittedly, a key characteristic of local authorities relevant to this study is their constitutionally-vested powers to formulate and implement germane local public policies capable of resolving economic-related problems in their area while satisfying the needs of their constituents (Helmsing, 2003). In addition to delivering basic services within their territory, local government authorities' devolved powers afford them the capacity to develop policies and structures that shape their neighbourhoods (Shah, 2006). Undoubtedly, such supremacies have the potential to stimulate business-related activities effectively boosting a local economy and ultimately improving the livelihood of the indigenous population (Grant and Dollery, 2010; DFID, 1999). In line with this, the debates at the Commonwealth Local Government Conference in Cardiff in 2011 attended by about five hundred delegates from fifty one countries recognised the principal role performed by local governments in enabling and coordinating local development strategies that promote economic opportunities while contributing towards achieving economic development goals (Wekwete, 2014). In light of this, the main purpose for undertaking this research is:

- To examine the role performed by the metropolis of Chegutu in stimulating the development of its local economy and

- To explore various systems of governance contributing or impeding the metropolis of Chegutu's efforts to expedite its economic development.

In order to achieve the above-mentioned objectives this research utilised the case of the metropolis of Chegutu. A survey was carried out with a view to develop an understanding of the processes followed by elected council officials of the metropolis who are given the authority to improve the economic performance of their local area. 
The concept of LED is not a new phenomenon; it has been practiced in industrialised countries for decades (Blair el al., 1984; Judd and Parkinson, 1990; Molotch and Viacri, 1988). In low-income countries such as Zimbabwe the fundamentals of LED need to be re-examined given their considered role in stimulating economic development (Burger, 1997; Helmsing, 2003; Grant and Dollery, 2010). This is deemed necessary in this study especially for Zimbabwe in the sense that, the Southern African country was once labelled the 'bread basket' of Africa (Mudzonga and Chigwada, 2009). Quite clearly, prevailing systems of national governance appear to have severely weakened local governance structures in Zimbabwe and, yet evidence indicates that there is a strong correlation between localised strategic planning and economic prosperity (Ascani et al., 2012; DFID, 1999).

To use the wider context of Southern Africa evidence exists confirming the positive impact of localised economic processes of development to local and regional economies. For example, Pallangyo and Rees (2010) explained how Tanzania through its local government reform programs initiated by the central government authorities have had a positive impact on human resource development, organization development, and institutional development dimensions in its cities. In South Africa LED policies were experienced in forms ranging from urban entrepreneurialism to rural survival strategies (Nel, 2001; Wekwete, 2014). Denkler (2009) demonstrated how the community-based natural resource management program in Botswana improved the livelihood of people living in the villages of Mabele, Kavimba, Kachikau, Satau, and Parakarungu. Eiseb et al. (2014) highlighted how the public-private dialogue meetings were adopted in Namibia as a platform for diagnosing problems and opportunities for economic development. While these trajectories of economic development are increasingly embedded into systems of local and central governance in other low-income countries, the extent to which such systems have been established to maximise economic development processes in Zimbabwe is yet to be fully explored. The Chegutu case study seeks to plug-in aspects of this research gaps. 
Quite clearly, the case of the metropolis of Chegutu is particularly fascinating to use as the main stage for probing localised economic development processes in Zimbabwe because the town is known for its capacity to create opportunities for the business community and its constituents (Magure, 2014). The main goal is to exact our understanding of the economic development tools and strategies currently employed by the municipal committee and their strategic 'fit' in a fast-deteriorating economy.

\section{RESEARCH CONTEXT}

The urban local authority at the centre of this study is part of a wider system of government in Zimbabwe. This system of government provides the institutional environmental context within which local authorities function described in Burger (1997, p.79) as a 'unitary system'. According to Chatiza (2010) Zimbabwe's local governments had a subservient role to the central government - a system embedded in its history. The external institutional environment imposed some of the key parameters which delineated the spectrum of capacity of the local authorities through enabling and disabling institutions (Chakaipa, 2010). It is therefore particularly important in a study of policy-performance relationships to have an appreciation of the system within which urban local authorities operate.

\section{Local governance in Zimbabwe}

Depending on one's perspective it is a thought-provoking activity to establish when exactly to start the narrative of local government in a Zimbabwean context (Chatiza, 2010). There are different versions in the literature regarding the starting point of the historical accounts of the local government in this low-income country (Chakaipa, 2010). One school suggests that local government started from time immemorial as local communities always existed in Zimbabwe under different types of traditional local governments (Hammar, 2003). 
Another body of knowledge takes the view that the story of local government begun with the advent of colonialism in Zimbabwe (Brand, 1991). Whichever viewpoint one approves, it is undeniable that local governance in Zimbabwe has undergone significant changes over time. Quite clearly, colonialism transformed the way communities were governed in colonial Zimbabwe. Therefore, there is logic in suggesting that the current system of local governance in Zimbabwe is anchored on the doctrines of the economic development practices of its colonial masters.

\section{The history of Chegutu Municipality}

Archived documentary evidence in the town hall with dates covering the period between 1900 and 1903 highlight that Chegutu Town (then known as Hartley) was established in 1900 after the discovery of gold in the district by a hunter called Henry Hartley at Butterfly and Giant mines. It was at the very location of the above-mentioned mines where the town was first established and in 1902 it was repositioned along the Mupfure (Umfuli) river which has remained its current day location. In 1903 Chegutu proclaimed a Village Board and evidence archived in the town hall suggested that it was the only Village Board in the country to have exclusively elected members. It operated as a village board up until the early 1940s. In 1942 Chegutu was proclaimed a Town Management Board under the Municipal Act of 1930. This allowed the town to operate as a board until 1974. The same year marked a significant transformation in the governance structures of Chegutu in the sense that, the metropolis attained municipal status effectively making the town a municipality within the statute of the Urban Councils Act 1973 under Chapter 214 directive. Upon attaining the municipality status Chegutu was effectively bestowed control and ownership of expansive open land measuring about 3100 hectares which they named Hartley Township Reserve. 
In light of the historical narrative of Chegutu, is it evident that the metropolis was established as a consequence of the discovery and subsequent mining of minerals particularly gold. Quite clearly, the metropolis was set up as a mining town to serve the interests of miners at Butterfly mine and Giant mine although it later became a major agricultural hub saving the interests of white farmers living in the broad hinterland of Chegutu. Even to the current day agriculture and mining remain the key pillars of the metropolis' economy. In terms of its legal structure, the metropolis of Chegutu is legally a corporate body set up under the Urban Councils Act of 1996 under Chapter 29:15 directives. This firmly places it within the confines of a municipality implying that the metropolis is a second tier local authority (Wolman and Spitzley, 1996) within the framework of the legislation governing urban councils (Rural District Councils Act, 1996 and the Urban Councils Act, 1996). Chegutu is one of five municipal councils in the country. The other municipalities are Gwanda, Kariba, Redcliff, Chitungwiza and Marondera (Wekwete, 1991). In the context of regional demarcations the metropolis of Chegutu is located in the Mashonaland West Province and it is the third largest urban settlement in the province after Chinhoyi and Kadoma. The metropolis is $35 \mathrm{~km}$ from Kadoma and $90 \mathrm{~km}$ from Chinhoyi the largest city in Mashonaland West Province. In relation to Harare its proximity is estimated to be $100 \mathrm{~km}$ to the south west along the Harare-Bulawayo highway.

\section{Chegutu's local economy}

In response to the broader national decline in economic opportunities there has been growth in the informal sector (Magure, 2014) in Chegutu as people are experiencing economic hardships with limited or no apparent alternative livelihood strategies. The currently leading employment sectors appear to be farming and social services. Noticeably, the prevailing economic practices in Chegutu seem to be heavily reliant on agriculture and mining activity in the hinterland. Evidence emanating from the town hall suggested that economic activity in the town is on the decline. 
A major employer David Whitehead Textiles ceased its operations in 2009 and Cargill another key agent of economic development in the region commenced scaling down operations in the first half of 2014 while several other businesses large and small have ceased to operate due to viability problems emanating from the difficult economic environment in Zimbabwe (Parliamentary Research Document, 2011). The metropolis of Chegutu has very high levels of unemployment as evidenced by the large informal sector in Zimbabwe's urban towns (Tamukamoyo, 2009). Chegutu exists within the category of municipalities with weak economic structures and mass poverty (Chegutu Municipality Master Plan: Draft Report of Study, 1998). The local council operates in very difficult circumstances. As indicated in its internal reports (Councils minutes, 2013) the major challenges facing Chegutu municipality are:

- $\quad$ Financial viability

- $\quad$ Large population of which 90\% are considered poor

- $\quad$ Service provision backlogs and deteriorating infrastructure

- $\quad$ Limited staff capacity

Notably, the town hall appears to be facing severe cash flow problems making it difficult for the municipal committee to meet its obligations to creditors and employees for several months (Councils minutes, 2013). It has an employee salary backlog of seven months and is burdened by an external debt in excess of five million United States dollars (Council financial reports, 2013).

\section{Population dynamics}

Chegutu municipality has a fairly large population of approximately 50,590 inhabitants (GeoHive, 1996-2013). Fifty three percent (53\%) of the population can be described as female. The activity rate for the population is $44.66 \%$ meaning a significant part of the population in Chegutu is unemployed and they benefit from the informal sector. 
The population is projected to grow to 75000 by 2025 because of a number of factors that include:

- Rural-urban migration of the youthful population is contributing to large population influx.

- The proposed establishment of a Tertiary Education Institution (Chegutu University) is expected to generate a multiply effect in the increased demand for residential stands and other ancillary uses connected therewith.

- Mining activities-ZIMPLATS, Global Platinum Resources, Pickstone Peerless Mine amongst other mining companies have a key interest in carrying out housing and other developmental projects.

- The anticipated industrial revival thorough the ZIMASSET (value addition and beneficiation cluster) is anticipated to result in both increased industrial activities within the existing processing industries (David Whitehead Textile Factory) and the emergency of new industries requiring industrial space to operate. All these elements are expected to contribute to increased job opportunities.

Source: Archived council reports

\section{Key issues}

Statistically the metropolis of Chegutu's is an area with a fairly large concentration of people. Chegutu is a town with a considerably low formal economic activity rate as a result of the closure of a few large companies that used to operate in the town. This has resulted in a thriving informal business sector (Magure, 2014). It is however, important to note that Chegutu is surrounded by large mining conglomerates such as Zimbabwe Platinum Mines and Global Platinum Mines which operate within its locale. A rather alarming observation concerning the metropolis of Chegutu is that, it does not have a strong existing economic base which can be used as a platform for further economic growth. The metropolis can be classified as having a weak economic structure and as such, the need to tackle, head-on, issues of economic development in the town is ever-increasing. 
The challenges of high unemployment and poverty; severe financial shortages render the creation of economic growth and employment an imperative. In light of this, it makes more sense to explore the role performed by the metropolis of Chegutu in terms of its actions towards improving/reviving its declining local economy. In so doing, we provide some insight into the efforts or lack of effort on the part of the local authorities to halt the ostensible decline of the town.

\section{Theoretical framework}

To capture the common features of the processes adopted in developing local economies in a low-income country we apply the sustainable livelihood approach (DFID, 1999). The sustainable livelihood framework was deemed appropriate for purpose of this study because it encompasses key LED components pertinent to the metropolis of Chegutu as illustrated on figure 1 p.10. Other relevant concepts of LED were presented by the World Bank (2008b). The World Bank conceptualised LED as a process designed to stimulate economic activity in a local area as well as shape the economic future and the quality of life for all. Another concept related to this study was provided by Chambers and Conway. Chambers and Conway (1992) conceptualise a livelihood as consisting of 'capabilities, assets (stores, resources, claims and access) and activities required for a means of living contributing net benefits to other livelihoods at the local and global levels and in the long and short term' (1992, p.7). In considering these viewpoints and evidence emanating in the metropolis of Chegutu we developed a nuanced theoretical framework sketching the localised process of economic development. The refined model takes its origins from the widely used model of sustainable livelihood framework proposed first by the Department for International Development (DFID) in 1999. The sustainable livelihood framework was adopted for the purpose of this study because of its ability to contribute to the better understanding of various mechanisms of the process of planning new development actives. 
Most importantly, its ability to facilitate the assessment of various factors that influence local economic development. The newly developed model below can be a useful template for LED in low-income coutries.

- Insert Figure 1 about here -

The modified framework (a localised process of economic development) presented above embodies that various factors which influence economic development perform a pivotal role in enabling and disabling LED through transformational structures and processes. Specifically, the process of developing a local economy is conceptualised as significantly enhanced or undermined by how various systems influencing economic development including: human capital $(\mathrm{H})$, social capital $(\mathrm{S})$, natural capital $(\mathrm{N})$, physical capital $(\mathrm{P})$ and financial capital $(\mathrm{F})$ relate to each other. Crucially, the inter-connectedness of various components in an economic system is influenced, to a great extent, by the transforming structures and processes.

Quite clearly, transforming structures and processes are central to the economic development of local economies. Notably, the framework demonstrates that the process of LED is shaped by policies, institutions and processes and these take into account the individual, local and national levels. Furthermore, the transforming structures and processes regulate various types of capital (human, social, natural, physical and financial) as well as economic development. They also define strategic options for LED and access to decision-making bodies and external sources of influence. As denoted on the framework processes determine the way in which institutions and key individuals cooperate and coordinate to achieve the desired outcomes presented as; entrepreneurship and small businesses development, retention and expansion of existing businesses, job creation, and promotion of social and economic equity. 


\section{METHODOLOGY}

The methodology adopted for this study is validated by the ontological and epistemological paradigms (Guba and Lincoln, 1994). The ontological viewpoint authenticating this study affirms that social phenomena (LED) and its meaning are constantly brought into being by the actions of Chegutu's council officials. As such, within the ontological paradigm framework we were able to ascertain the relationships between development strategies (council official actions) and local economic development (social phenomena) in a low-income country using quantitative measures. This lends itself more to a positivist approach - allowing the study to gather data about observable reality of the governance structures and processes in the metropolis of Chegutu. The positivist lens facilitated an experiment-like examination of the conditions in the metropolis' economic environment and the chain relationships (Miles and Huberman, 1994) between various factors influencing economic development, transforming structures and processes and the desired outcomes of economic development strategies. The primary goal was to generate law-like (Johnson and Christensen, 2010) generalisations about the processes of economic development in low-income countries. The epistemological paradigm, which is related to studying the nature of knowledge (Bryman et al., 2008), facilitated the interpretations of various systems militating economic development in the metropolis of Chegutu. In that sense, this study was also influenced by the traditions of interpretivism.

An interpretive approach is often associated with studies of a qualitative nature (Punch, 2013) as such, a case study strategy was utilised to provide rich data (Yin, 2009) about the metropolis of Chegutu. The case-oriented approach was useful in that, we were able to develop an in-depth insight into the processes of economic development and the current economic climate within the metropolis of Chegutu. Therefore, the selection of Chegutu as the setting for this study was an important step of the research because the town's economic structures are typical of an average commercial town in a low-income country. 
More so, the research was able to examine the key economic-related systems militating Chegutu's economic development in a real life context (Farquhar, 2012; Eisenhardt, 1989; Robson, 2002; Yin, 2003). The main advantage realised by adopting a case-based research was concomitant with its ability to facilitate triangulation (Gray, 2013; Mason, 2002) i.e. the research applied various methods of data collection. Specifically, empirical evidence was collected using a survey research technique, archived documented evidence in the town hall detailing the history of the metropolis, and observations of the activities of the key participants were useful at the data collection stage.

Survey questionnaires were distributed to key informants in the metropolis of Chegutu. Stratified random sampling which represents a combination of simple random sampling and systematic sampling (Dattalo, 2010) was used to enable the research to achieve a wider range of representation in terms of the key informants in Chegutu and for reducing the degree of sampling error (Gray, 2013). The sample was divided into two main clusters. The first category consisted of council officials. Precisely, 21 council officials were recruited to participate in the research. The participants ranged from the mayor, deputy mayor, 6 ward councillors, town clerk, 3 head of departments, 5 senior managers/professionals and 4 general employees.

The second category comprised of members of the business community. The reason for choosing this second group of participants was to increase the validity of the narratives given by the council officials. From that perspective, 25 members of the business community were chosen from a wide range of business domains including: agricultural production, manufacturing, retail trade, the service sector and the construction industry. The participants included as part of the business community varied from business owners to general employees. Another reason for selecting a large pool (46) of participants across the board was to increase the strength of our inferences and the extent to which they can be generalised (Bellamy and Perri, 2009). 
Collected data was stored in a statistical software package (SPSS) IBM version 22 which was then used to produce statistical results presented in the following sections.

\section{RESULTS}

\section{Planning and accountability}

The responding participants were asked to indicate whether the metropolis of Chegutu was responsible for developing its locality. A significant percentage $(85.7 \%)$ well above three quarters of the participants who were employed by the second tier government agreed that the town house was, to a greater extent, responsible for the local economic development of Chegutu as illustrated on Table 1 below.

- Insert Table 1 about here -

This shows that there was consensus among council officials regarding who, in their opinion, was influential in the process of developing their district. Many regional and urban studies researchers universally recognise that local authorities are important institutions in the process of developing local, regional, and national economies (Shah, 2006; Bunker, 1983; Haque, 1997; Nooi, 2008; Wekwete, 2014; World Bank, 2008a). When responding to questions regarding the most important role performed by the local government in developing Chegutu's economy over $80 \%$ of the informants expressed that it should create a positive business climate as well as provide high quality public services and amenities. Table 2 on p.14 neatly illustrates their views. The table also shows that about $19 \%$ of the informants believed that the local council in the metropolis of Chegutu should provide strategic leadership and proactively facilitate the process of economic development. From this, it appeared council officials were aware of the duty of the city council. Further research is however necessary to ascertain the level of influence of the key council officials on the strategy development process within the local council. 
That is, the extent to which their views regarding local economic development initiatives are considered by the policy-making body (elected council committee) of the metropolis of Chegutu.

- Insert Table 2 about here -

\section{Chegutu's local economy}

When it comes to the issue of driving economic development efforts, in the metropolis of Chegutu, there was significant variation as to what the town council was focusing on as illustrated on Table 3 below.

- Insert Table 3 about here -

Seven top council officials $(33.3 \%)$ signified that the focus of the municipality's economic development efforts was on the manufacturing sector. Just below a quarter (19\%) were of the view that the emphasis was on agricultural development. Two other groups accounting for about $28.6 \%$ of the council officials in the sample felt that much of the efforts of the town council were warehousing/distribution services and the retail sector. This discrepancy in opinions concerning the level of importance of economic development efforts of the metropolis of Chegutu perhaps suggests that there was lack of common understanding and vision on the development thrust of the metropolis among council officials. The results above are unequivocal. If these key individuals in the town house do not share the same vision as projected in their perceptions, it can be said that the process of economic development in the metropolis of Chegutu is mired, to an extent, by a lack of focus in strategic formulation. For economic development to occur at grassroots levels elected council officials must develop a coherent and sustained development policy in Chegutu. Rather worryingly, there was convincing evidence indicating that the metropolis of Chegutu does not have a written strategic plan for economic development. 
Table 4 below shows that a large percentage $(76.2 \%)$ of the council officials was not aware of the existence of a strategic plan for economic development in Chegutu. In addition to this, the same percentage of the council officials indicated that the committee does not carry out a systematic evaluation of its economic development efforts. In light of this Chegutu can be classified as having dysfunctional, inefficient and ineffective structures to measure and monitor the impact of its development initiatives.

- Insert Table 4 about here -

\section{Economic development strategies and tools}

The individual activities and tools which appeared to be widely used by the metropolis of Chegutu to support broad economic development strategies included: business recruitment, business retention and expansion and small business creation and entrepreneurship development. When recruiting new businesses to invest in Chegutu, promotion and advertising were cited by the council officials $(57.1 \%)$ as the main strategies frequently used. Below half of the council respondents $(47.6 \%)$ indicated that trade shows and conferences were also utilised for this purpose. This demonstrates, to a certain extent, that the council officials are making some effort to attract businesses to Chegutu. While this was positive in terms of the building blocks of a localised process of economic development the councils' business retention and expansion strategy provided a contrasting view. About $52.4 \%$ of the respondents of the 21 council officials specified that there were existing partnerships with non-government organisations (NGOs) in Chegutu, 33\% highlighted that these collaborations were done with other local authorities and 19\% showed that there were partnering arrangements with existing business industries. The same percentage $(19 \%)$ agreed that there were no business retention activities occurring in Chegutu. Data on business retention appeared to suggest a low level of municipal activity in business retention and expansion activities. 
This therefore indicates that the elected committee primarily charged with developing Chegutu does not have a proactive approach to business retention and expansion. In terms of entrepreneurship and small business development strategies respondents in Chegutu's business community felt that the most prevalent and related activities/methods were collaborative marketing (52.4\%) and land subsidisation for business expansion (33.3\%). Other significant responses were reported indicating that small business development centres (28.6\%) were routinely utilised as well as 'business incubators' (19\%). Quite clearly, such a result signifies that there is a low level of municipal support to small businesses. This can be further explained by the limited range of strategies for facilitating the development and growth of small but enterprising businesses. This is backsliding and yet for a metropolis the size of Chegutu nascent firms can perform a key role in developing its economy by creating wealth and jobs. It was felt within the business community that the support provided to small businesses is less satisfactory.

- Insert Table 5 about here -

Table 5 above illustrates that a significant number $(60 \%)$ of a representative sample of the business community were of the view that the metropolis' support to small business was poor, $28 \%$ indicated that it was fair while less than a tenth $(8 \%)$ felt it was acceptable. This implies that the metropolis must develop policies to transform the districts' economic environment by supporting key developmental activities.

\section{DISCUSSION OF FINDINGS}

The survey findings reported in this study suggested there was a high degree of awareness among council officials that it was the metropolis of Chegutu that has the primary responsibility for economic development of the town. This responsibility translates to a single most important role of creating a positive business climate which enables private investment, economic growth and employment creation. From that perspective, local authorities can be viewed as key enablers of economic development in their local area. 
Another key finding of this study was that the metropolis of Chegutu lacks a strategic approach to LED. Specifically, evidence highlighted that the town house does not have a written strategic plan and it does not evaluate its economic development activities. Furthermore, it was found that the metropolis of Chegutu does not make use of key accountability mechanisms such as performance agreements, cost benefit analysis and eligibility criteria. Quite clearly, this unstructured approach to local economic development best described as 'shooting at anything that flies past and claiming anything that falls to the ground relegates the metropolis to a severely diminished role in promoting LED in Chegutu.

Taking into account the wider context of LED international experience suggests that economic development should be guided by systematic planning and strategic focus. Cities, towns and communities now need to be more strategic in their approach to economic development. Therefore, for a local authority to succeed in fostering LED, it needs to have a range of clearly defined goals and objectives which should form the basis for specific strategies and tools to employ to develop its locality. As such, a local authority with a strategic approach to local economic development should exhibit evidence signifying the use of strategic planning, strategy evaluation and other accountability mechanisms such as cost benefit analysis and performance agreements as already highlighted in the study. Being strategic in LED means selecting the strategies and tools that are best suited to a community's goals using safeguards to protect the public investment and measuring success/failure.

In the context of Chegutu, the results also revealed that the metropolis was still reliant on the traditional economic development strategies of business recruitment, business retention and small business development. Evidently, the main tools relied upon for business recruitment by the metropolis were flaccid responses to business prospects and attendance at conferences and trade shows. 
For business retention, the metropolis entered into strategic alliances with NGOs, other local authorities and local business publicity programs. The partnering strategy was aberrant to the metropolis given its unstructured approach to the economic development activities in the district. Notwithstanding the fact that the metropolis appeared to lack scope and direction in terms of developing Chegutu, there was a myriad of challenges and impediments hindering its efforts. The survey pointed towards a lack of capital/funding, severely depleted numbers of major employers within the metropolis, a lack of infrastructure development and the nonexistence of political support for economic development initiatives as the topmost problems. Logically speaking, these challenges further goaded the metropolis' economic degeneration.

\section{CONCLUSIONS}

LED is a function of local level capacity and resources that are available for promoting private investment within a locality. The capacity to promote economic growth also depends on the external assistance the local authority can take advantage of. The survey findings suggested the local authority had both resource and capacity limitations and this was maybe the main reason why it appeared to be doing less to promote local economic development. Furthermore, survey data provided convincing evidence indicating that the metropolis was doing less because it had fewer financial, human and organisational resources. Four themes emerged from the survey results and the study of economic development activities in Chegutu. The first was related to the capacity of the metropolis of Chegutu to revive the economy of its area. It was clear that the town was less engaged in efforts to shape Chegutu's economy. This was further exacerbated by a host of precincts identified as: a critical shortage of capital, a lack of political leadership and management (as highlighted in the nuanced model on p.10. It can therefore be concluded that LED (summed here as the attraction of major employers, provision of infrastructure and attainment of political and citizen support in the case of Chegutu) is a function of resources (capital and leadership capacity). 
From this, it is reasonable to conclude that for a local authority in a low-income country to be effective in LED it needs access to critical resources such as capital as well as human resources in the form of leadership and management. The second theme emerging from the result and the literature was that collaboration and cooperation (through joint ventures, partnerships, and other collaborative arrangements) rather than competition between development organizations improves the capacity of a local authority in particular, access to external resources necessary for infrastructure development in the absence of local financial resources. From that point of view, challenges such as those related to lack of infrastructure require new approaches and innovations in capital development financing (joint venture arrangements, public-private partnerships, and special purpose vehicles) in the absence of adequate financial capital.

The third theme and the overarching subject was related to the development of businesslike relationships. An important part of local capacity building for economic development involves linking local communities to valuable ideas, resources and opportunities. The linkages that matter most are those that promote local innovation, facilitate desired change, produce results and help a local community accomplish what it cannot do alone. A competitive posture disconnects a local authority from key valuable networks e.g. from the international community which appears to be shunned by the central government in Zimbabwe and yet, such networks could be very useful for a localised process of economic development. From this we conclude that, local, national and international networks are a valuable source of ideas and resources. Stronger network connections between the above-mentioned levels can be a way of expanding the capacity for economic development at the local level. Indeed, local authorities should endeavour to remain connected to the central government while at the same time maintaining links with key institutions in the region, country and in the international arena in order that they tap into valuable and unique knowledge, skills and information. 
Even so, the metropolis of Chegutu represented a town with disjointed local policies hugely misaligned with the national economic development policies and the wider international community. Based on this, it is paramount that a framework for economic interaction in Chegutu be established to enable networking with the central government, between local authorities and the international community to enhance its ability to economically develop its neighbourhood.

\section{KEY RECOMMENDATIONS}

In light of the results and the inferences of this study we recommend key strategies deemed appropriate for elevating the metropolis of Chegutu from its economic morass.

(1) The decision-making body in the metropolis of Chegutu should focus on capacity building through extensive training in strategic planning and economic development. Given that Zimbabwe follows a unitary system (Burger, 1997) of governance, it is imperative that the central government ensures a wider appreciation of economic development issues in the metropolis of Chegutu and that the process of stimulating economic development at the local level is systematic and proactive. Admittedly, a perpetual disconnection between national economic and local economic development programs often lead to a continued spiral into poverty and a waste of limited resources. Crucially, the metropolis of Chegutu should be forthright in improving access to critical resources such as land, labour and capital to nascent businesses as they can be a vehicle for economic development. 
(2) Leadership is a critical element in economic development. The imperfections in local council leadership (within the metropolis of Chegutu) appeared to be arising from the disabling provision of local government legislation (Urban Councils Act 1996; Chapter 29:15) which removed minimum qualification criteria to allow the selection of councillors on a first past the post system negating the need for capable leadership. It is important that policy-makers such as the central government considers the need to infuse capable leadership in the electoral systems of local authorities. The national system of using proportional representation in the appointment of members of the Senate holds promise at the local level. An opportunity exists for redressing this deficiency through the need to realign the Urban Councils Act 1996; Chapter 29:15) to the new Constitution.

\section{LIMITATIONS}

The results presented herein are deemed valuable and insightful. However, we acknowledge the limitations inherent with adopting a single case oriented approach within an exploratory research framework. In that sense, there is need for an in-depth research on the subject beyond the scope of a single case study to allow the inferences to be generalised to a much larger population.

\section{REFERENCES}

Ascani, A., Crescenzi, R., and Iammarino, S. (2012). Regional Economic Development: A Review, WP1/03 SEARCH WORKING PAPER, European Commission: Europe Research Area FP7 Project. Available at: http://ledna.org/sites/ledna.org/files/regional development a review.pdf. Accessed on $12 / 11 / 2014$

Bellamy, C., and Perri, 6. (2009). Principles of Research Design: A Guide to Methodology in Social Science, Sage Publications Inc., London

Blakely E. J., (1994). Planning Local Economic Development: Theory and Practice, $2^{\text {nd }}$ Edition (48), Thousand Oaks: Sage Publications.

Blair, J. P., Fichtenbaum, R. H., and Swaney, J. A., (1984). The Market for Jobs Locational Decisions and the Competition for Economic Development. Urban Affairs Review, 20(1), 64-77. 
Brand, C., (1991) "Will decentralization enhance local participation?" Jeffery in A. H. J. Helmsing, N. D. Mutizwa- Mangiza, D. R. Gasper, C. M. Brand and K. H. Wekwete Riedinger, (Eds.), Limits to Decentralization in Zimbabwe (Harare, "Decentralization Zimbabwe: University of Zimbabwe, 1991). pp. 79-96.

Bryman, A., Becker, S. and Sempik, J., (2008). Quality Criteria for Quantitative, Qualitative and Mixed Methods Research: A View from Social Policy. International Journal of Social Research Methodology, 11(4), 261-276.

Bunker, R., (1983). Urban Consolidation: The Experience of Sydney, Melbourne and Adelaide. Australian Institute of Urban Studies, AIUS Publication No. 111, Canberra.

Burger, J. (1997). A strategic development management orientation for local authorities, Development Southern Africa, 14(1), 79-96.

Chakaipa, S., (2010). Local government institutions and elections, Local government reform in Zimbabwe: A Policy Dialogue, State, Peace and Human Security Studies, Edited by Jaap de Visser, Nico Steytler and Naison Machingauta. Community Law Centre, Zimbabwe.

Chatiza, K., (2010). "Can Local Government Steer Socio-economic Transformation in Zimbabwe?" in Visser de J., Steytler, N. \& Machingauta, N. (eds.), Local Government reform in Zimbabwe: A policy dialogue. Bellville (South Africa): Community Law Centre (University of Cape Town).

Chegutu Municipality, (1998); Chegutu Master Plan: Background Report of Study. Chegutu Town House. Unpublished Report.

Chambers, R., and Conway, G., (1992). Sustainable rural livelihoods: practical concepts for the 21 st century. Institute of Development Studies. IDS Discussion Paper 296, Brighton: UK.

Council Financial Report, (2013). Chegutu Town Council. Unpublished report.

Council Minutes, (2013). Chegutu Town House, Unpublished documentation.

Cuba, E. G., and Lincoln, Y. S. (1994). Competing Paradigms in Qualitative Research, In N. K. Denzin and Y. S. Lincoln (Eds) Handbook of Qualitative Research ( $2^{\text {nd }}$ Edition): 407-508, Thousand Oaks, CA: Sage.

Dattalo, P., (2010). Ethical dilemmas in sampling. Journal of Social Work Values and Ethics, 7(1), 12 23.

Department for International Development (DFID), (1999). Sustainable Livelihoods Guidance Sheets, DFID, London.

Denkler, J. L. (2009). Community Based Natural Resource Management: Power, Isolation, and Development in Rural Botswana (Doctoral dissertation, University of Florida).

Eiseb, E, Shifotoka, H. and Kamwi, L., (2014). PPD as part of the Local Economic Development (LED) Initiative in Namibia, Presented at the Public-Private Dialogue 2014 Workshop (Frankfurt, March 3-6 2014), Available at: 
http://www.publicprivatedialogue.org/workshop $\% 202014 /$ Public $\% 20$ Private $\% 20$ Dialogue $\% 20 \mathrm{i}$ n\%20Namibia.pdf. Accessed 27/10/2014

Eisenhardt, K., (1989). Building theories from case study research. Academy of Management Review, 14(4), 532- 50.

Farquhar, J. W., (2012). Case-study Research for Business, Sage Publications: London

GeoHive, (1996-2014). Zimbabwe General Information, Available at:

http://www.geohive.com/cntry/zimbabwe.aspx. Accessed 17/11/2014

Grant, B and Dollery, B., (2010). Place-shaping by local government in developing countries: Lessons for the developed world. International Journal of Public Administration, 33, 251-61.

Gray, D. E. (2013). Doing research in the real world. Thousand Oaks, CA: Sage Publications.

Hammar, A., (2003). The Making and Unma(s) king of Local Government in Zimbabwe, in Zimbabwe's Unfinished Business: Retbinking Land, State and Nation in the Context of Crisis, A. Hammar, B. Raftopoulos and S. Jensen (Eds), Harare: Weaver Press, pp. 119-154.

Haque, M. S., (1997). Local Government in Developing Nations: Re-examining the Question of Accountability, Regional Development Dialogue, 18(2), pp. iii-xxiii.

Helmsing, A. H. J., (2003). Local economic development: new generations of actors, policies and instruments for Africa. Public Administration and Development, 23(1), 67-76.

Johnson, R. R. B., and Christensen, L. B., (2010). Educational research: Quantitative, qualitative, and mixed approaches. Sage Publications.

Judd, D., and Parkinson, M., (1990). "Patterns of Leadership". In D. Judd and M. Parkinson, eds., Leadership and Urban Regeneration Newbury Park, CA: Sage.

Kuklinski, A. R., (1970). Regional development, regional policies and regional planning, Regional Studies, 4(3), 269-278, Available at: http://dx.doi.org/10.1080/09595237000185291. Accessed $12 / 11 / 2014$.

Magure, B., (2014). Interpreting Urban Informality in Chegutu, Zimbabwe. Journal of Asian and African Studies, DOI: 10.1177/0021909614535568. Available online at:

http://jas.sagepub.com/content/early/2014/06/05/0021909614535568. Accessed on $12 / 10 / 2014$

Masson, J., (2002). Qualitative Interviewing. In May, T., (Ed), (2002), Qualitative Research in Action, London: Sage.

Miles, M, and Huberman, M., (1994). Qualitative data, Thousand Oaks: Sage Publications,

Molotch, H., and Viacri, S., (1988). Three ways to build the development process in the United States, Japan and Italy, Urban Affairs Quarterly, 24, 188-214

Mudzonga, E., and Chigwada, T., (2009). A case study of Zimbabwe's food security. Agriculture: Future Scenarios for Southern Africa, Trade Knowledge Network, International Institute for Sustainable Development 
Nel, E. (2001). Local economic development: A review and assessment of its current status in South Africa. Urban Studies, 38(7), 1003-1024.

Nooi, P. S., (2008). Decentralisation or Recentralisation? Trends in local government in Malaysia. Commonwealth Journal of Local Government, 1, 126-132.

Pallangyo, W., and Rees, C. J., (2010). Local government reform programs and human resource capacity building in Africa: evidence from local government authorities (LGAs) in Tanzania. International Journal of Public Administration, 33(12-13), 728-739.

Parliament Research Department, (2011). Chegutu East Constituency Profile, the Clerk of Parliament, the Parliament of Zimbabwe.

Punch, K. F., (2013). Introduction to social research: Quantitative and qualitative approaches. Thousand Oaks, CA: Sage Publications.

Republic of Zimbabwe (1996): Rural District Councils Act Chapter 29: 13. Harare. Government Printers

Republic of Zimbabwe (1996): Urban Councils Act Chapter 29: 15, Harare: Government Printers.

Robson, C., (2002). Real World Research, Second Edition, Oxford, Blackwell

Shah, A., (2006). Local governance in developing countries. Public Sector Governance and Accountability Series. The International Bank for Reconstruction and Development, World Bank Publications.

Tamukamoyo, H., (2009). Survival in a collapsing economy: A case study of informal trading at a Zimbabwean flea market. Unpublished PhD Thesis, University of the Witwatersrand, Johannesburg, Department of Sociology.

Wekwete, K. H., (1991). Decentralised Planning in Zimbabwe: A Review of Provincial, Urban and District Development Planning in Post-Independence Zimbabwe. In Helmsing et al. Limits to Decentralisation in Zimbabwe, ISS, The Hague.

Wekwete, K. H., (2014). Local Government and Local Economic Development in Southern Africa. Draft for discussion at the Southern African Regional Conference 'Creating opportunity for developmental local government through regional engagement on Local Economic Development' Lilongwe, Malawi, Paper prepared for the Commonwealth Local Government.

Wolman, H., and Spitzley, D., (1996). The politics of local economic development. Economic Development Quarterly, 10(2), 115-150.

World Bank (2008a) Realizing Rights through Social Guarantees: An Analysis of New Approaches to Social Policy in Latin America and South Africa.

World Bank (2008b) Increasing Social Inclusion through Social Guarantees: A Policy Note.

Yin, R. K., (2003). Case-study Research: Design and Methods, $3^{\text {rd }}$ Edition, Thousand Oaks, CA: Sage Publications. 
Yin, R. K., (2009). Case-study Research: Design and Methods, $4{ }^{\text {th }}$ Edition, Thousand Oaks, CA: Sage Publications

Figure 1: A localised process of economic development

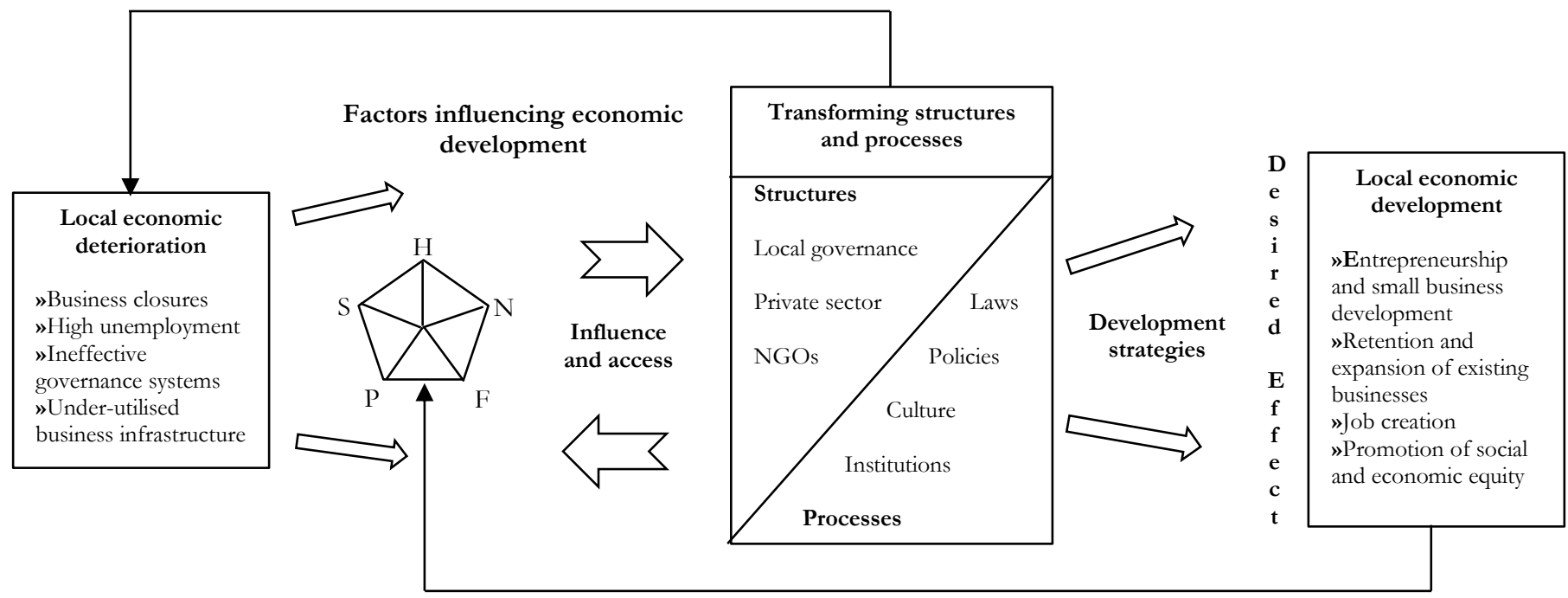

Source: DFID, 1999 and authors' ideas

Table 1: The responsible institution for economic development in the metropolis of Chegutu

\begin{tabular}{|c|c|c|c|c|c|}
\hline & & Frequency & Percent & Valid Percent & $\begin{array}{l}\text { Cumulative } \\
\text { Percent }\end{array}$ \\
\hline Valid & & 1 & 4.8 & 4.8 & 4.8 \\
\hline & Chegutu Municipality & 18 & 85.7 & 85.7 & 90.5 \\
\hline & No single organization & 1 & 4.8 & 4.8 & 95.2 \\
\hline & Other (specify) & 1 & 4.8 & 4.8 & 100.0 \\
\hline & Total & 21 & 100.0 & 100.0 & \\
\hline
\end{tabular}

Table 2: The most important role performed by the local government in developing Chegutu's economy

\begin{tabular}{|l|r|r|r|r|}
\hline & Frequency & Percent & Valid Percent & $\begin{array}{c}\text { Cumulative } \\
\text { Percent }\end{array}$ \\
\hline Valid & 1 & 4.8 & 4.8 & 4.8 \\
$\begin{array}{c}\text { create positive business } \\
\text { climate } \\
\text { provide high quality public } \\
\text { services and amenities }\end{array}$ & 8 & 38.1 & 38.1 & 42.9 \\
\hline
\end{tabular}




\begin{tabular}{|c|c|c|c|c|}
\hline $\begin{array}{l}\text { provide strategic leadership } \\
\text { and proactively facilitate } \\
\text { the process }\end{array}$ & 4 & 19.0 & 19.0 & 100.0 \\
\hline Total & 21 & 100.0 & 100.0 & \\
\hline
\end{tabular}

Table: 3 Primary focus of economic development efforts in the metropolis of Chegutu

\begin{tabular}{|c|c|c|c|c|c|}
\hline & & Frequency & Percent & Valid Percent & Cumulative Percent \\
\hline \multirow[t]{8}{*}{ Valid } & & 1 & 4.8 & 4.8 & 4.8 \\
\hline & Agricultural & 4 & 19.0 & 19.0 & 23.8 \\
\hline & Manufacturing & 7 & 33.3 & 33.3 & 57.1 \\
\hline & Retail/Service & 3 & 14.3 & 14.3 & 71.4 \\
\hline & $\begin{array}{l}\text { Residential/Bedroom/Com } \\
\text { munity }\end{array}$ & 2 & 9.5 & 9.5 & 81.0 \\
\hline & Warehousing/Distribution & 3 & 14.3 & 14.3 & 95.2 \\
\hline & Retirement Community & 1 & 4.8 & 4.8 & 100.0 \\
\hline & Total & 21 & 100.0 & 100.0 & \\
\hline
\end{tabular}

Table 4: Existence of a written strategic plan for economic development

\begin{tabular}{|ll|r|r|r|r|}
\hline & & & & \\
& & Frequency & Percent & Valid Percent & Cumulative Percent \\
\hline Valid & 1 & 4.8 & 4.8 & 4.8 \\
& Yes & 4 & 19.0 & 19.0 & 23.8 \\
& No & 16 & 76.2 & 76.2 & 100.0 \\
& Total & 21 & 100.0 & 100.0 & \\
\hline
\end{tabular}

Table 5: Business community evaluation of municipal support to small business development in Chegutu

\begin{tabular}{|l|r|r|r|r|}
\hline & Frequency & Percent & Valid Percent & \multicolumn{2}{c|}{$\begin{array}{c}\text { Cumulative } \\
\text { Percent }\end{array}$} \\
\hline Valid poor & 15 & 60.0 & 60.0 & 60.0 \\
& 7 & 28.0 & 28.0 & 88.0 \\
fair & 2 & 8.0 & 8.0 & 96.0 \\
good & 1 & 4.0 & 4.0 & 100.0 \\
excellent & 25 & 100.0 & 100.0 & \\
Total & & & & \\
\hline
\end{tabular}

